\title{
Blood cell gene expression associated with cellular stress defense is modulated by antioxidant-rich food in a randomised controlled clinical trial of male smokers
}

\author{
Siv K Bøhn ${ }^{1}$, Mari C Myhrstad ${ }^{1}$, Magne Thoresen², Marit Holden³, Anette Karlsen', Siv Haugen Tunheim4, \\ Iris Erlund ${ }^{5}$, Mette Svendsen ${ }^{6}$, Ingebjørg Seljeflot ${ }^{7}$, Jan $\varnothing$ Moskaug $^{8}$, Asim K Duttaroy ${ }^{1}$, Petter Laake², \\ Harald Arnesen ${ }^{7}$, Serena Tonstad ${ }^{6}$, Andrew Collins', Christan A Drevon ${ }^{1}$, Rune Blomhoff ${ }^{*}$
}

\begin{abstract}
Background: Plant-based diets rich in fruit and vegetables can prevent development of several chronic age-related diseases. However, the mechanisms behind this protective effect are not elucidated. We have tested the hypothesis that intake of antioxidant-rich foods can affect groups of genes associated with cellular stress defence in human blood cells. Trial registration number: NCT00520819 http://clinicaltrials.gov.

Methods: In an 8-week dietary intervention study, 102 healthy male smokers were randomised to either a diet rich in various antioxidant-rich foods, a kiwifruit diet (three kiwifruits/d added to the regular diet) or a control group. Blood cell gene expression profiles were obtained from 10 randomly selected individuals of each group. Dietinduced changes on gene expression were compared to controls using a novel application of the gene set enrichment analysis (GSEA) on transcription profiles obtained using Affymetrix HG-U133-Plus 2.0 whole genome arrays.

Results: Changes were observed in the blood cell gene expression profiles in both intervention groups when compared to the control group. Groups of genes involved in regulation of cellular stress defence, such as DNA repair, apoptosis and hypoxia, were significantly upregulated (GSEA, FDR q-values $<5 \%$ ) by both diets compared to the control group. Genes with common regulatory motifs for aryl hydrocarbon receptor (AhR) and AhR nuclear translocator (AhR/ARNT) were upregulated by both interventions (FDR q-values $<5 \%$ ). Plasma antioxidant biomarkers (polyphenols/carotenoids) increased in both groups.
\end{abstract}

Conclusions: The observed changes in the blood cell gene expression profiles suggest that the beneficial effects of a plant-based diet on human health may be mediated through optimization of defence processes.

\section{Background}

The majority of plant chemicals (phytochemicals) are antioxidants. A predominantly plant-based diet reduces the risk for development of many chronic age-related diseases linked to oxidative stress, such as cancer and cardiovascular diseases [1,2]. The hypothesis that the antioxidant abilities of phytochemicals limit oxidative

\footnotetext{
* Correspondence: rune.blomhoff@medisin.uio.no

'Department of Nutrition, Institute of Basic Medical Sciences, Faculty of Medicine, University of Oslo, Norway

Full list of author information is available at the end of the article
}

damage caused by reactive oxygen species (ROS) has been tested in large clinical investigations with pharmacological doses of antioxidants (vitamin $\mathrm{C}$, betacarotene and vitamin E). However, these antioxidant supplementations have failed to prevent chronic diseases and in some cases actually worsen the outcome $[3,4]$. These results are interesting but not contradictory to a biological function of plant food antioxidants. In contrast to antioxidant supplements that contain single or a few antioxidants, plant food contains thousands of different phytochemicals with various antioxidant content and
C Biomed Central 
chemical properties. It is possible that a variety of antioxidants at physiological concentrations is required for a beneficial health effect. It is also likely that phytochemicals modulate signal transduction and gene expression related to protective networks via antioxidant as well as through nonantioxidant activities [5,6]. Several phytochemicals can regulate the expression of genes involved in cellular defence via the antioxidant responsive element (ARE/EpRE) by activation of the transcription factor NFE2L2/Nrf2 (nuclear factor (erythroid-derived 2)-like $2 /$ nuclear factor erythroid 2-related factor 2) [7]. Notably, vitamin $C, \beta$-carotene and vitamin $E$ are not particularly efficient inducers of NFE2L2 $[8,9]$. Through evolution, aerobic organisms have acquired inducible networks of genes for protection against damaging effects of ROS $[5,6,10]$ and for repair thereof $[11,12]$. On the other hand, compelling evidence indicates that ROS is an important mediator, for example, of proper cell signalling, homeostasis control, cell turnover [13]. It has been proposed that oxidative challenges induce adaptive/hormetic responses responsible for the healthpromoting effects of physical exercise. Intake of antioxidant supplements during exercise has prevented health-promoting effects of physical exercise in humans [14]. It is possible that ROS as well as plant food substances induce gene expression related to adaptive responses of cellular defence. Removal of ROS by highdose single antioxidants without the concomitant induction of adaptive/hormetic responses, such as defence and repair processes, may explain the disappointing results of antioxidant supplements on disease prevention. It is also possible that high-dose antioxidants have pro-oxidative effects.

As an approach to identify food with potential beneficial health effects, we have screened more than 3500 different foods for total antioxidant capacity [15]. On the basis of these results, we designed an antioxidant-rich diet including berries, nuts and seeds, spices, certain fruits and vegetables to test the hypothesis that plant food substances induce gene expression related to adaptive responses of cellular stress defence. We also examined whether adding three kiwifruits daily to a regular diet could induce similar effects. In kiwifruit, the majority of measurable total antioxidant content [15] is contributed by one antioxidant (vitamin C) [16].

\section{Methods}

\section{Study design and intervention}

The study followed a randomised group design with 8 weeks of intervention. Healthy male smokers were recruited via an advertisement in a local newspaper.

The inclusion criteria were men between 45 and 75 years of age, smoking at least 5 cigarettes daily and $\mathrm{BMI}<35 \mathrm{~kg} / \mathrm{m}^{2}$ with stable weight range for the past
6 months. The exclusion criteria were any symptomatic cardiovascular disease (CVD), diabetes (type 1 or type 2), following a vegetarian or near-vegetarian diet, allergy to any items of the intervention or clinically diagnosed disorders, including gastrointestinal diseases. Moreover, participants with a history of serious or unstable medical or psychiatric disorder, current users or those in need of lipid-lowering drug treatment, aspirin or nonsteroidal anti-inflammatory drugs, nutritional supplements or herbs for weight loss within 4 weeks prior to inclusion or participating in a drug trial during the previous 30 days were not included. Participants were included between March 2004 and March 2005. The Easter holiday, summer vacation and Christmas holiday were avoided to prevent possible confounding by seasonal changes in the participants' diets.

The 102 included participants were randomly assigned to the two intervention groups and the control group, with 34 in each group. Randomization was performed in blocks of 12, with group allocation provided in presealed, numbered envelopes. One group received an antioxidant-rich diet while another group received three kiwifruits daily. The antioxidant-rich diet food items were included in exchange for foods in their habitual diet. The food exchange was discussed with the study nutritionist, but the participants were free to select which foods to replace. The kiwifruits were added to the habitual diet. The control subjects continued their habitual diet with a few restrictions (e.g., limitation to coffee intake). In total, 100 participants completed the study ( $n=34$ in the control group and $n=33$ in both the intervention groups). Blood samples were collected at Oslo University Hospital, Ullevål, Norway. Ten individuals from each group were randomly chosen for gene expression analysis of whole-blood RNA using Affymetrix Human Genome U133 Plus 2.0 arrays. All statistics on baseline characteristics and plasma biomarkers in this paper are given for this subgroup only.

The subjects in both intervention groups received food items weekly. In the antioxidant group these included green tea, dog rose juice, cranberry juice, aronia juice, unsweetened bilberry juice, bilberry jam, bilberries, blackberries, strawberries, raspberries, pomegranate, dark blue grapes, Brussels sprouts, broccoli, red cabbage, kale, blue potatoes, tomatoes, dark chocolate, bread with pecan nuts and sunflower seeds, walnuts, olive oil, rosemary, thyme and oregano. The kiwifruit group received a bag of 21 kiwifruits. Weekly amounts of the food items provided to the antioxidant-rich diet group are listed in Table 1. The foods that were not consumed were registered weekly in a custom-made questionnaire. Subjects in the control group were monitored at followups every second week. For whole-blood genome analysis, samples were collected using PAXgene Blood RNA 
Table 1 Antioxidant-rich food items provided to the antioxidant-rich diet group during the intervention period

\begin{tabular}{|c|c|c|c|}
\hline Food item & Manufacturer & $\begin{array}{l}\text { Food items provided } \\
\text { weekly }\end{array}$ & $\begin{array}{l}\text { Total antioxidants provided } \\
\text { in foods, } \mathrm{mmol} / \mathrm{wk}\end{array}$ \\
\hline Green java tea & Twinings (London, UK) & 7 tea bags & 20.86 \\
\hline $\begin{array}{l}\text { Juice of rose hips, orange, apple and carrot (Mana } \\
\text { yellow) }\end{array}$ & Tine BA (Oslo, Norway) & $1.66 \mathrm{~L}$ & 42.64 \\
\hline $\begin{array}{l}\text { Juice of cranberries, raspberries and grapes (Mana } \\
\text { Red) }\end{array}$ & Tine BA (Oslo, Norway) & $1.66 \mathrm{~L}$ & 10.95 \\
\hline $\begin{array}{l}\text { Juice of black chokeberry, bilberries, grapes and } \\
\text { cherries (Mana Blå) }\end{array}$ & Tine BA (Oslo, Norway) & $1.66 \mathrm{~L}$ & 33.18 \\
\hline Bilberry juice (Vaccinium myrtillus) & Corona Safteri (Ranheim, Norway) & $0.66 \mathrm{~L}$ & 54.73 \\
\hline Bilberry jam (Vaccinium myrtillus) & Heistad (Bergen, Norway) & $345 \mathrm{~g}$ & 10.50 \\
\hline Bilberries (Vaccinium myrtillus) & Odd Langdalen Engros & $200 \mathrm{~g}$ & 16.24 \\
\hline Blackberries (Rubus fruticosus) & Odd Langdalen Engros & $200 \mathrm{~g}$ & 9.20 \\
\hline Strawberries (Fragaria $\times$ ananassa) & Odd Langdalen Engros & $200 \mathrm{~g}$ & 4.26 \\
\hline Raspberries (Rubus idaeus) & Odd Langdalen Engros & $200 \mathrm{~g}$ & 5.87 \\
\hline Pomegranate (Punica granatum) & Odd Langdalen Engros & $200 \mathrm{~g}$ & 3.43 \\
\hline Dark blue grapes (Vitis sp.) & Odd Langdalen Engros & $200 \mathrm{~g}$ & 2.23 \\
\hline Brussels sprouts (Brassica oleracea var. gemmifera) & Odd Langdalen Engros & $200 \mathrm{~g}$ & 2.01 \\
\hline Broccoli (Brassica oleracea var. italica) & Odd Langdalen Engros & $200 \mathrm{~g}$ & 1.93 \\
\hline Red cabbage (oleracea var. capitata rubra) & Outdoor cultivar $^{a}$ & $200 \mathrm{~g}$ & 3.82 \\
\hline Kale (Brassica oleracea var. sabellica) & Outdoor cultivar $^{a}$ & $200 \mathrm{~g}$ & 4.71 \\
\hline Blue potatoes (Solanum tuberosum, 'Blue congo') & $\begin{array}{l}\text { Odd Langdalen Engros (Oslo, } \\
\text { Norway) }\end{array}$ & $150 \mathrm{~g}$ & 0.00 \\
\hline Tomatoes (Solanum lycopersicum) & $\begin{array}{l}\text { Odd Langdalen Engros (Oslo, } \\
\text { Norway) }\end{array}$ & $700 \mathrm{~g}$ & 2.24 \\
\hline Dark chocolate, $70 \%$ cocoa & Kraft Foods (IL, USA) & $100 \mathrm{~g}$ & 11.22 \\
\hline Pecan nuts (Carya illinoinensis) ${ }^{b}$ & $\begin{array}{l}\text { Den lille nøttefrabrikken } \\
\text { (Fredrikstad, Norway) }\end{array}$ & $100 \mathrm{~g}$ & 8.30 \\
\hline Sunflower seeds (Helianthus annuus) ${ }^{b}$ & $\begin{array}{l}\text { Den lille nøttefrabrikken } \\
\text { (Fredrikstad, Norway) }\end{array}$ & $100 \mathrm{~g}$ & 6.31 \\
\hline Walnuts (Juglans californica) ${ }^{\mathrm{b}}$ & Diamond Foods Inc (CA, USA) & $200 \mathrm{~g}$ & 44.48 \\
\hline Extra Virgin Olive Oil (Olea europaea) ${ }^{c}$ & Ybarra (Toano, Spain) & $0.063 \mathrm{~L}$ & 0.19 \\
\hline Rosemary (Rosmarinus officinalis) ${ }^{c}$ & Black Boy (Bergen, Norway) & $3 \mathrm{~g}$ & 1.55 \\
\hline Thyme (Thymus vulgaris) ${ }^{c}$ & Black Boy (Bergen, Norway) & $3 \mathrm{~g}$ & 1.69 \\
\hline Oregano (Origanum vulgare gracile) ${ }^{c}$ & Black Boy (Bergen, Norway) & $3 \mathrm{~g}$ & 1.90 \\
\hline Total antioxidants per week & & & 304.43 \\
\hline
\end{tabular}

${ }^{\mathrm{a}}$ Food items were provided by The Norwegian University of Life Sciences (Ås, Norway).

${ }^{b}$ Food items were provided as ingredients in a bread.

${ }^{c}$ Food items were provided once, at the start of the intervention period.

Tubes (QIAGEN, Cat. No. 762115) at the time of randomization and at the end of the intervention period. All investigators performing sample analyses or statistics were blinded until statistical analyses were performed. The study was approved by the regional ethics committee for medical research (REK Sør), and all participants gave their written, informed consent. The study is registered at http://clinicaltrials.gov with Identifier NCT00520819. The trial registry name is 'Oslo Antioxidant Study'.

\section{Comparison of baseline characteristics and dietary intake} Kruskal-Wallis one-way analysis of variance was used to evaluate whether baseline values or changes during the intervention period differed between the groups. Where significant results were obtained using Kruskal-Wallis, a Mann-Whitney nonparametric test was performed to compare the median values between the groups. Changes during the intervention period were calculated by subtracting the baseline value from the postintervention value. All statistics were performed using SPSS version 14.0. A $P$ value of 0.050 or below was considered statistically significant.

\section{Plasma antioxidants}

Quercetin was analysed by high-performance liquid chromatography (HPLC) and electrochemical detection after enzymatic hydrolysis as described elsewhere [17]. 
Phenolic acids and enterolactone were analysed by gas chromatography-mass spectrometry after enzymatic hydrolysis using a modification of a previously described method [18].

A full description of the methods for plasma carotenoid analyses is included in Additional file 1, document S1. The plasma carotenoids (lutein, zeaxanthin, $\beta$-kryptoxanthin, $\alpha$-carotene, $\beta$-carotene and lycopene) were analysed for all groups while the polyphenol (quercetin, phenolic acids and enterolactone) analysis was performed for the antioxidant-rich diet group and control group only, because intake of kiwifruit was not expected to affect changes in these parameters.

\section{Microarray analysis}

An overview of the experimental approach and strategy for data analyses is presented in Figure 1. RNA from whole blood was isolated according to the PAX kit

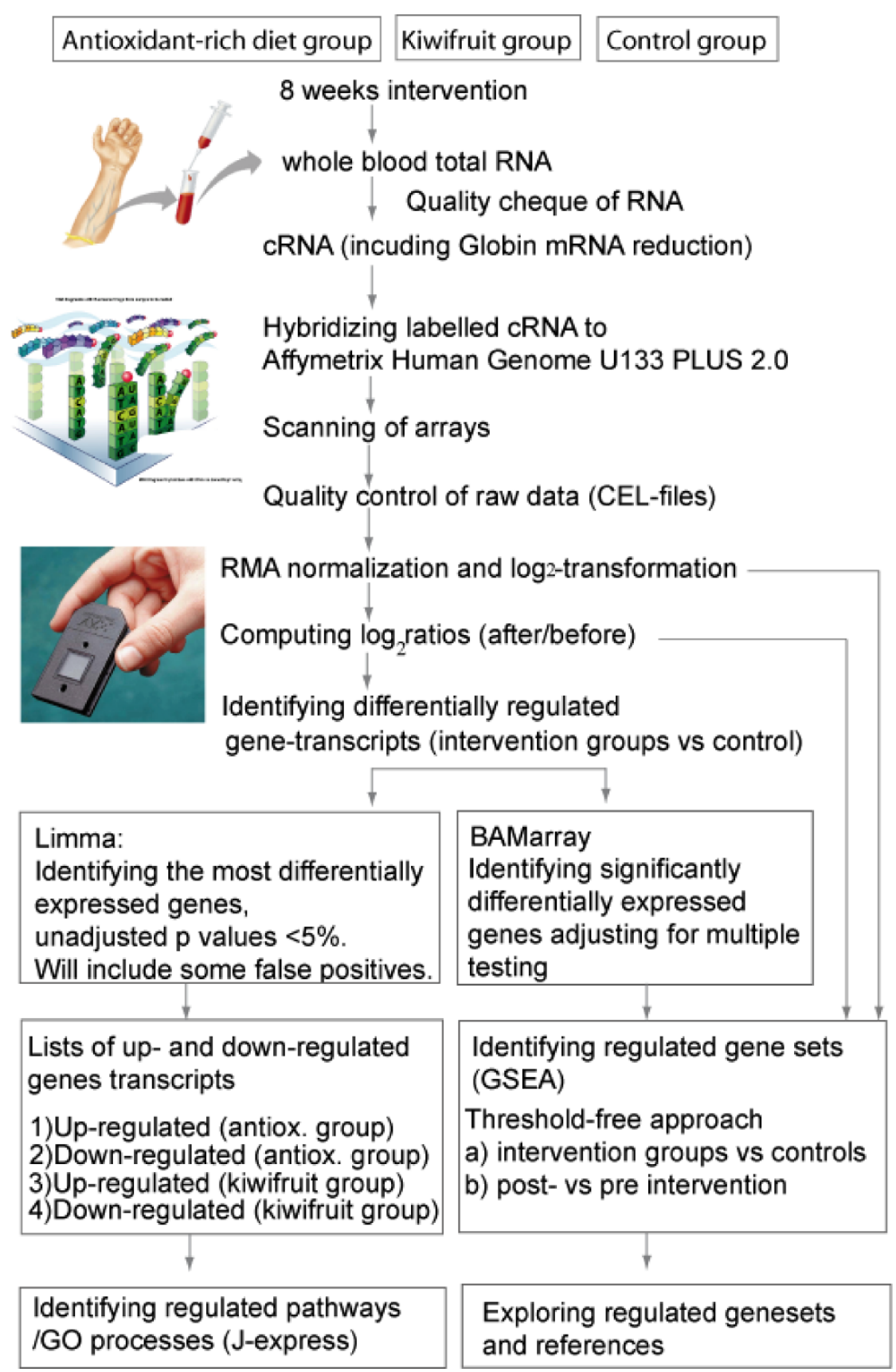

Figure 1 Overview of the experimental approach and strategy for data analyses. (Images courtesy of Affymetrix Inc.) 
manufacturer, including the optional on-column DNase digestion. All samples in the subgroup used for microarray analysis $(n=30)$ had excellent RNA integrity as judged by Bioanalyzer and sufficient yield ( $>10 \mu \mathrm{g}$ RNA). Affymetrix one-cycle gene expression protocol was performed according to Affymetrix (Santa Clara, CA) by including the step of globin transcription reduction (GeneChip globin reduction, Affymetrix). The globin reduction oligos (PNA oligos) were purchased from Applied Biosystems. All other reagents were purchased from Affymetrix. Affymetrix Human Genome U133 Plus 2.0 arrays were used to obtain whole-blood RNA expression profiles. Labeled cRNA was analysed by Bioanalyzer and Nanodrop before fragmentation and hybridization to the arrays. To verify that reverse transcription of globin mRNA was successfully blocked, RNA was analysed by gel electrophoresis (data not shown).

\section{Microarray data analysis}

Minimum Information About a Microarray Experiment (MIAME) standards http://www.mged.org/Workgroups/ MIAME/miame.html were followed in the analysis and storage of data. The raw data are available at the ArrayExpress at http://www.ebi.ac.uk/microarray-as/ae/ at accession number E-MEXP-2030. Arrays were scanned using GeneChip Scanner 3000 7G (Affymetrix). Image analysis was performed using GeneChip Operating Software 1.3 (Affymetrix). Libraries from http:// www.bioconductor.org (e.g., affy, simpleaffy, affyPLM, arrayQuality) implemented in the MADMAX quality control pipeline https://madmax.bioinformatics.nl were used to assess the quality of the arrays in the experiment. Arrays from one subject in the kiwifruit group were removed due to evident hybridization problems. For every gene, the change in gene expression during the intervention were obtained by calculating $\log _{2}$ ratios between the before and after intensities using Robust Multichip Average (RMA) normalised intensities. The intervention groups were then compared to the controls with regard to this ratio. Percentage change for each gene and maximum fold induction and reduction were calculated.

Probe set annotation was last updated on 12 March 2009 via the NetAffx on the Affymetrix web site http:// www.affymetrix.com/analysis/index.affx. The basic local alignment search tool (BLAST) for aligning two nucleotide sequences was utilised for identification of the probe sets target sequences, and the BLAST database was used for identification of sequences of the differentially expressed genes.

\section{Differentially expressed genes}

A specialised Bayesian analysis of variance (ANOVA) method for microarrays, BAMarray http://www.
BAMarray.com, which accounts for the problem of multiple testing, was used to find significantly differentially expressed genes [19].

\section{Pathway analysis}

To create lists of differentially regulated gene transcripts for identification of biological processes, we applied a moderated $t$-test using $\mathrm{R}$ (version 2.6.1) and Linear Models for Microarray data [20] (Limma package from http://www.Bioconductor.org) on the RMA-normalised $\log _{2}$ ratios of the three groups (control group, antioxidant-rich diet group and kiwifruit group). The differentially expressed genes were divided into up- and downregulated gene transcripts for both intervention groups, thus producing four different lists. The threshold for including gene transcripts in the lists was an unadjusted/nominal $P$ value $\left(P_{\text {nom }}\right)$ of $<5 \%$.

For further downstream analysis, we used J-express provided by http://www.molmine.com. Fisher's exact test was used to explore whether the distribution of processes or pathways as defined by the Gene Ontology consortium http://www.geneontology.org in a subset of genes may be expected by chance when compared with a reference. Files required to run the application were downloaded from http://www.geneontology.org according to the instructions. The gene abbreviations used were those of the (Human Genome Organisation) HUGO gene nomenclature committee.

\section{Gene set enrichment analysis (GSEA)}

GSEA was used to identify whether an a priori defined set of genes (e.g., a pathway) shows concordant statistically significant differences between two biological states (e.g., diet intervention vs. control) [21]. Collections of gene sets were obtained using a gene set browser from the Broad Institute website http://www.broad.mit.edu/ gsea/. This browser searches a number of publicly available sources (e.g., Biocarta, Kegg) where genes are grouped if they belong to the same pathway and share ontology terms or clinical phenotypes. Thus, it is possible to define specific gene sets on the basis of a particular parameter of interest. We created 10 collections of gene sets using the following keywords stepwise: 'DNA AND repair'. Apoptosis', 'cytokine*', 'inflammation', interleukin*', 'immune* AND response', 'Hypoxi*', 'Stress', 'Stress AND response' and 'Oxidative AND stress'. The large, predefined gene set collection C3-TFT (transcription factor targets) version 2.5 from http://www.broad.mit.edu/ gsea/ [22] was also used. The C3 TFT collection consists of gene sets that contain genes that share a transcription factor binding site defined in the TRANSFAC (version 7.4, http://www.gene-regulation.com/).

GSEA was performed using J-express according to the description on the J-express manual. The gene matrix 
was collapsed by selecting the maximum probes. $\mathrm{T}$ statistics were used as the scoring method, the number of permutations was set to 1000 and gene sets with less than 10 genes or more than 500 genes were excluded from the analysis. False discovery rate (FDR) $q$ values $<5 \%$ were used as criteria for significantly enriched gene sets. Leading edge genes contributing to the significance of the regulated gene sets associated with DNA and repair were analysed using MetaCore from GeneGo Inc. http://www.genego.com/, an integrated software suite for functional analysis of biological experimental data.

\section{Results}

\section{Participant characteristics}

Of the 100 participants who completed the study $(\mathrm{n}=$ 34 in the control group and $n=33$ in both the intervention groups), 10 individuals from each group were randomly chosen for microarray analysis (Figure 2).

Participants in the microarray subgroups of the antioxidant-rich diet $(\mathrm{n}=10)$, kiwifruit $(\mathrm{n}=9)$ and control groups $(\mathrm{n}=10)$ were not significantly different at baseline with respect to age, BMI and the number of cigarettes smoked per day (Kruskal-Wallis) (Table 2). There were no significant differences between the three groups at baseline concerning intake of energy, alcohol, total fat, polyunsaturated fatty acids (PUFA), monounsaturated fatty acids (MUFA), saturated fatty acids (SFA), protein or carbohydrates (Kruskal-Wallis; data not shown).

\section{Plasma antioxidants}

Plasma antioxidants increased in both intervention subgroups (Tables 3 and 4) compared to controls, indicating successful dietary intervention. The significant median increase in plasma concentrations in the antioxidant-rich diet group were as follows: lutein (37\%), $\alpha$ carotene $(221 \%), \beta$-carotene $(50 \%)$, vanillic acid $(30 \%)$, protocatechuic acid (36\%), 3,4-dihydroxyphenyl acetic acid (DOPAC) (19\%) and gallic acid (94\%). The following polyphenols showed a trend for increase: quercetin (105\%, $P=0.11)$ homovanillic acid $(20 \%, P=0.08)$ and $p$-coumaric acid $(68 \%, P=0.08)$. A significant decrease was observed for zeaxanthin $(-22 \%)$. In the kiwifruit group, increases that were significantly different from

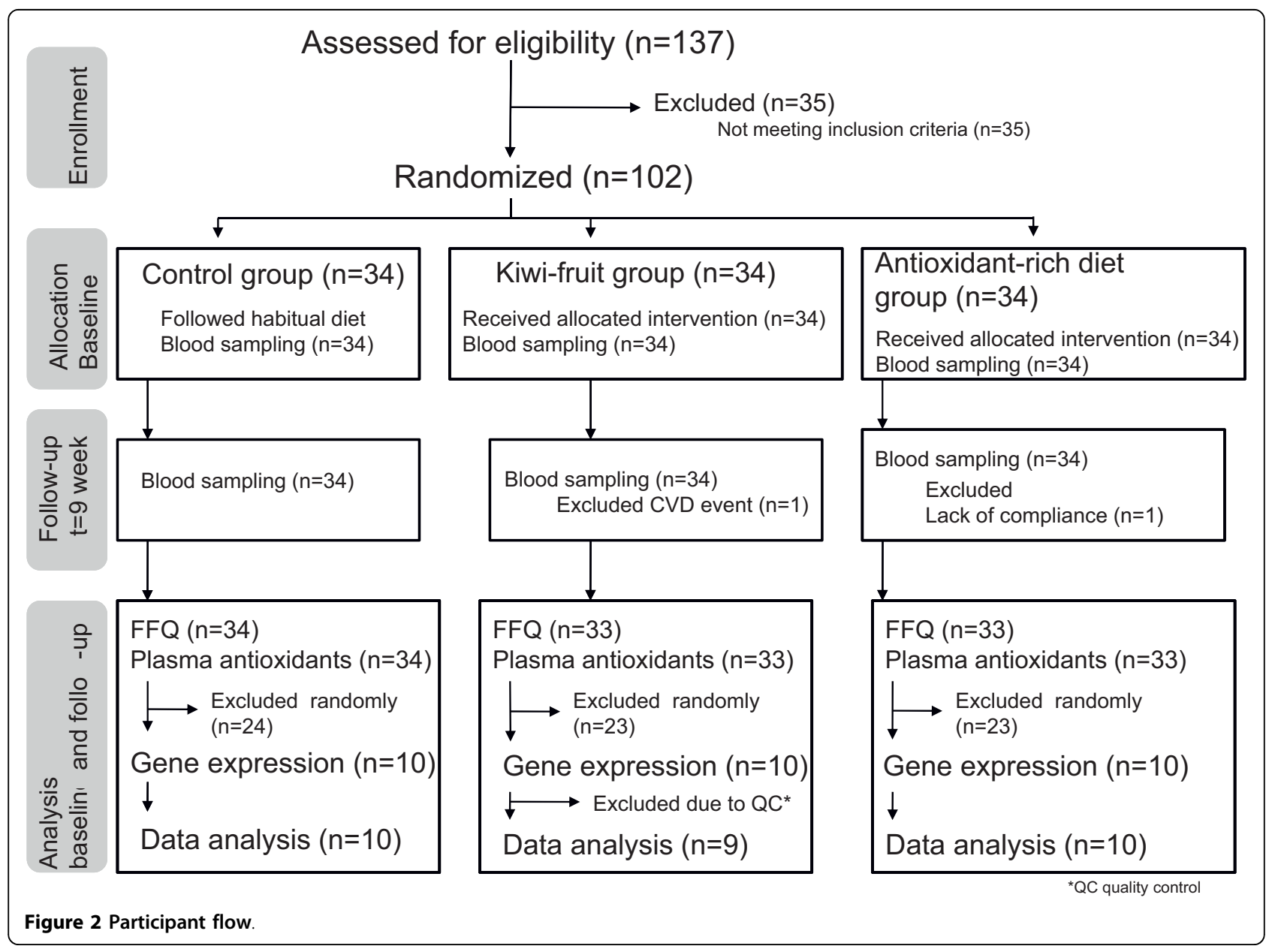


Table 2 Baseline characteristics

\begin{tabular}{|c|c|c|c|c|c|c|c|}
\hline \multirow[b]{2}{*}{ Age (yr) } & \multicolumn{2}{|c|}{$\begin{array}{l}\text { Control group } \\
(n=10)\end{array}$} & \multicolumn{2}{|c|}{$\begin{array}{l}\text { Antioxidant-rich diet group } \\
(\mathrm{n}=10)\end{array}$} & \multicolumn{2}{|c|}{$\begin{array}{l}\text { Kiwifruit group } \\
(\mathrm{n}=9)\end{array}$} & \multirow{2}{*}{$\begin{array}{c}\boldsymbol{P} \text { value } \\
0.3\end{array}$} \\
\hline & 56.0 & $(49.0-61.0)$ & 59.0 & $(53.0-63.0)$ & 57.0 & $(53.0-62.0)$ & \\
\hline Cigarettes $(n / d)$ & 18.0 & $(10.0-20.0)$ & 11.6 & $(5.0-20.0)$ & 18.0 & $(10.0-20.0)$ & 0.5 \\
\hline BMI $\left(\mathrm{kg} / \mathrm{m}^{2}\right)$ & 25.6 & $(22.1-28.6)$ & 25.6 & $(22.9-26.2)$ & 23.5 & $(22.3-28.4)$ & 0.8 \\
\hline
\end{tabular}

Group median with $95 \%$ confidence interval. A Kruskal-Wallis test was used to compare the groups.

control group were lutein (37\% increase) and $\beta$-kryptoxanthin (-33\% decrease).

\section{Gene expression profiling}

Figure 1 describes the experimental approach and the strategy for data analyses. Changes in gene expression in the intervention groups during the 8-week intervention were compared to the control group. We identified significantly differentially expressed genes and biological processes and pathways modulated by the dietary interventions. The methods used are based on different approaches to the statistical analysis as well as to how the gene transcripts are grouped. While GSEA was used to test the specific hypothesis that groups of genes involved in stress and defence processes were changed during the intervention period, the gene ontology (GO) analysis on regulated gene lists is a more descriptive method.

\section{Identification of significantly differentially expressed genes}

By applying BAMarray, we identified 44 gene transcripts as differentially expressed in the antioxidant-rich diet group as compared to the control group (adjusted for multiple testing). In the kiwifruit group, nine gene transcripts were significantly altered compared to the control group. The maximum induction of gene transcripts in the antioxidant-rich diet group was $77 \%$, whereas the kiwifruit group had a maximum increase of $37 \%$. The maximum reduction was $34 \%$ in the antioxidant-rich diet group and $23 \%$ in the kiwifruit group.
Twenty-six of the differentially expressed genes in the antioxidant-rich diet group were identified as encoding proteins with known chromosomal location and function (Table 5). The identified gene transcripts are known to be associated with processes such as signal transduction, lipid metabolism, transcriptional regulation, intracellular transport, cytoskeleton organization and inflammatory response. Two of the downregulated gene transcripts, hormone-sensitive lipase (LIPE) and glycerol kinase 2 (GK2), are targets for the nuclear receptor, peroxisome proliferator-activated receptor- $\gamma$ (PPAR $\gamma)$ and are involved in lipid metabolism. In addition, the nuclear receptor subfamily 0 (NR0B1) known as a PPAR $\gamma$ corepressor was also downregulated compared to the control group. Several of the downregulated transcripts represent genes involved in signal transduction, including the two G protein-coupled receptors: bitter taste receptor (TAS2R16) and olfactory receptor 2 (OR2F1). The probe ID 1567015_at which was significantly downregulated is annotated NFE2L2 nuclear factor (erythroidderived 2)-like 2 by the NetAffx from Affymetrix. However, we performed a BLAST aligning approach and found this probe ID to be wrongly annotated. Five of the nine gene transcripts that were significantly altered in the kiwifruit group are annotated with known functions (Table 6) and are associated with signal transduction ( $G$ protein-coupled receptor 173 (GPR173) (down), creatine kinase muscle (CKM) (down), catenin- $\delta$ (CTNND1) (up)), ion transport (Na ${ }^{+} / \mathrm{H}^{+}$exchanger domain containing 1 (NHEDC1 (up))

Table 3 Plasma carotenoids (nmol/L) and biomarkers of carotenoid-rich dietary items

\begin{tabular}{|c|c|c|c|c|c|c|c|c|c|c|c|c|c|}
\hline \multirow[b]{3}{*}{ Lutein } & \multicolumn{4}{|c|}{ Control group $(n=10)$} & \multicolumn{4}{|c|}{ Antioxidant-rich diet group $(n=10)$} & \multicolumn{4}{|c|}{ Kiwifruit group $(n=9)$} & \multirow{3}{*}{$\begin{array}{c}P^{\mathbf{a}} \\
0.07^{b}\end{array}$} \\
\hline & \multicolumn{2}{|c|}{ Baseline } & \multicolumn{2}{|c|}{ Change } & \multicolumn{2}{|c|}{ Baseline } & \multicolumn{2}{|c|}{ Change } & \multicolumn{2}{|c|}{ Baseline } & \multicolumn{2}{|c|}{ Change } & \\
\hline & 0.13 & $(0.08-0.18)$ & 0.00 & $(-0.03-0.04)$ & 0.14 & $(0.11-0.20)$ & 0.05 & $(0.00-0.12)$ & 0.14 & $(0.08-0.22)$ & 0.05 & $(-0.02-0.07)$ & \\
\hline Zeaxanthin & 0.03 & $(0.02-0.04)$ & 0.00 & $(-0.01-0.01)$ & 0.04 & $(0.02-0.06)$ & -0.01 & $(-0.03-0.00)$ & 0.03 & $(0.02-0.05)$ & 0.00 & $(-0.01-0.01)$ & $0.03^{c}$ \\
\hline$\beta$-cryptoxanthin & 0.07 & $(0.03-0.16)$ & 0.00 & $(-0.03-0.01)$ & 0.12 & $(0.06-0.23)$ & -0.05 & $(-0.13-0.01)$ & 0.08 & $(0.06-0.12)$ & -0.03 & $(-0.04-0.00)$ & 0.10 \\
\hline$\alpha$-carotene & 0.06 & $(0.03-0.09)$ & -0.01 & $(-0.04-0.00)$ & 0.03 & $(0.02-0.11)$ & 0.07 & $(0.00-0.18)$ & 0.07 & $(0.06-0.08)$ & -0.01 & $(-0.02-0.04)$ & $0.01^{c}$ \\
\hline$\beta$-carotene & 0.26 & $(0.22-0.38)$ & -0.04 & $(-0.26-0.05)$ & 0.16 & $(0.11-0.66)$ & 0.08 & $(-0.01-0.17)$ & 0.36 & $(0.13-0.52)$ & -0.05 & $(-0.11-0.07)$ & $0.02^{c}$ \\
\hline Lycopene & 0.50 & $(0.20-0.71)$ & -0.01 & $(-0.12-0.34)$ & 0.58 & $(0.30-0.88)$ & -0.10 & $(-0.41-0.14)$ & 0.57 & $(0.41-0.68)$ & 0.04 & $(-0.04-0.30)$ & 0.11 \\
\hline
\end{tabular}

Group median with $95 \%$ confidence interval.

${ }^{a}$ Kruskal-Wallis test was used to compare the changes between the groups. A Mann-Whitney test was used as post hoc test.

${ }^{\mathrm{b}}$ Change during intervention is significantly different between the kiwifruit group and controls.

'Significant difference between the antioxidant-rich diet group and controls. Baseline values were not significantly different between the groups $(P$ values not shown). 
Table 4 Plasma polyphenol concentrations (nmol/L)

\begin{tabular}{|c|c|c|c|c|c|c|c|c|c|}
\hline \multirow{3}{*}{$\overline{\text { Paraxanthin }}$} & \multicolumn{4}{|c|}{ Control $(n=10)$} & \multicolumn{4}{|c|}{ Antioxidant-rich diet $(n=10)$} & \multirow{3}{*}{$\frac{\boldsymbol{P} \text { value }^{\mathrm{a}}}{0.85}$} \\
\hline & \multicolumn{2}{|r|}{ Baseline } & \multicolumn{2}{|r|}{ Change } & \multicolumn{2}{|c|}{ Baseline } & \multicolumn{2}{|c|}{ Change } & \\
\hline & 3.2 & $(0.4-5.9)$ & -0.9 & $(-3.6-0.6)$ & 2.0 & $(0.0-7.1)$ & -0.5 & $(-3.3-0.2)$ & \\
\hline Quercetin & 24.5 & $(2.0-67.8)$ & 3.1 & $(-65.8-22.2)$ & 21.2 & $(2.0-54.6)$ & 22.2 & $(-0.9-193.6)$ & 0.11 \\
\hline 3-hydroxyphenyl acetic acid & 85.0 & $(28.9-605.7)$ & 15.6 & $(-309.4-91.4)$ & 92.3 & $(26.1-294.4)$ & 50.4 & $(-90.5-735.4)$ & 0.51 \\
\hline 4-hydroxyphenyl acetic acid & 500.6 & (376.1-1038.2) & -37.5 & $(-254.1-353.0)$ & 587.9 & $(400.5-923.6)$ & -106.4 & $(-497.7-225.9)$ & 0.68 \\
\hline Vanillic acid & 128.9 & $(99.0-679.5)$ & -41.0 & $(-153.3-42.1)$ & 118.7 & $(73.8-318.4)$ & 64.2 & $(-3.8-552.0)$ & 0.02 \\
\hline Protocatechuic acid & 112.5 & $(54.3-327.5)$ & -5.8 & $(-71.4-23.4)$ & 88.7 & $(61.8-156.1)$ & 31.9 & $(6.6-53.8)$ & $0.03^{*}$ \\
\hline Homovanillic acid & 95.6 & $(77.9-279.1)$ & -1.4 & $(-187.5-21.3)$ & 87.3 & $(77.6-144.0)$ & 17.3 & $(-21.6-255.5)$ & 0.08 \\
\hline 3,4-hydroxyphenyl acetic acid & 150.1 & $(92.6-199.8)$ & -5.5 & $(-89.4-24.8)$ & 158.4 & $(107.8-235.8)$ & 31.4 & $(-54.1-102.7)$ & 0.12 \\
\hline Gallic acid & 30.4 & $(16.0-63.3)$ & -4.6 & $(-28.9-20.7)$ & 21.7 & $(15.5-29.8)$ & 20.3 & $(0.8-39.8)$ & $0.01^{*}$ \\
\hline p-coumaric acid & 20.8 & $(11.9-110.2)$ & -6.5 & $(-65.0-1.8)$ & 15.3 & $(5.6-36.1)$ & 10.4 & $(-15.4-83.1)$ & 0.08 \\
\hline Caffeic acid & 203.1 & $(32.7-656.5)$ & -29.2 & $(-255.4-24.7)$ & 97.6 & $(36.8-193.5)$ & -10.4 & $(-112.0-232.4)$ & 0.31 \\
\hline Enterolactone & 18.1 & $(4.8-39.2)$ & 9.1 & $(-2.6-55.1)$ & 13.0 & $(6.2-50.6)$ & 10.5 & $(-4.7-40.6)$ & 1.00 \\
\hline
\end{tabular}

Biomarkers of polyphenol intake.

Group median with $95 \%$ confidence interval.

${ }^{a} \mathrm{~A}$ Mann-Whitney test was used to compare the change in the antioxidant-rich diet group compared to controls.

*Significant $P<0.05$. Baseline values were not significantly different between the groups. $P$ values not shown.

and immune functions (immunoglobulin $\kappa$ light chain variable region (NTN3) (down)).

\section{Identification of differentially regulated gene sets by GSEA}

GSEA was used to test the hypothesis that groups of genes involved in stress and defence processes were changed during the intervention period by comparing the two interventions to the control. A substantial number of 'stress'-related gene sets in the defined collections, as described in Methods section, were significantly upregulated in the intervention groups (Table 7).

The 'DNA and repair' collection, consisting of 61 gene sets, is the most convincing significantly upregulated gene set collection in both intervention groups as compared to the control group, with 15 and 13 gene sets upregulated in the antioxidant-rich diet group and kiwifruit group, respectively. Ten of these were overlapping between the intervention groups. As shown in Additional files 2. 3, 4, Figures S1-S3, the leading edge genes contributing to the significance of these gene sets are involved in different aspects of DNA repair such as nucleotide excision repair, mismatch repair and double-stranded break repair. Gene set collections related to hypoxia, and apoptosis were upregulated in both intervention groups with larger effects, i.e., a higher number of regulated gene sets in the antioxidant-rich diet group. Only one gene set in each of the three immune-related collections was upregulated in the antioxidant-rich diet group, while two immunerelated gene sets were upregulated in the kiwifruit group. One gene set related to immunoglobulin secretion was also found downregulated in the kiwifruit group. The 'stress', 'stress and response' and 'oxidative stress' collections were significantly upregulated in the antioxidant-rich diet group but not in the kiwifruit group. An overview of the regulated gene sets in each collection is provided as Additional files 5, 6, Tables S1 and S2, including a brief description of the differentially regulated gene sets with references. Additional information on the gene sets can also be obtained at http://www.broadinstitute.org/gsea/.

Paired GSEA tests comparing pre- and postintervention values within each group confirmed that the 'stress'-related gene sets were significantly upregulated in the intervention groups (Table 8). No gene sets related to DNA repair, hypoxia, stress response or oxidative stress were upregulated in the control group, whereas some immune-related gene sets were significantly modulated (both up- and downregulated).

To explore which regulatory mechanisms may be involved in the gene regulation induced by the two diets, we performed a GSEA analysis to test whether groups of genes with common regulatory motifs were differentially regulated. We found 13 significantly upregulated C3 transcription factor targets (TFT) gene sets in the antioxidant-rich diet group, of which six were known transcription factors (Additional file 7, Table S3). Two of these are genes containing the promoter motive for Yin-Yang transcription factor (YY1). The other represents genes with promoter motifs for GA binding protein transcription factor (GABP)/nuclear respiratory factor 2 (NRF2), member of the E-26 (ETS) oncogene family (ELK1) and aryl hydrocarbon receptor (AhR). Four C3 TFT gene sets were downregulated in the antioxidant-rich diet group. Two of these are grouped by similar promoter motives for known transcription factors; cutlike 1 (CUTL1) and RE1-silencing transcription 
Table 5 Genes that were significantly upregulated (positive z-score) and downregulated (negative z-score) in the antioxidant-rich diet group when compared to controls

\begin{tabular}{|c|c|c|c|}
\hline Probe id & z-score & Gene Symbol & Gene title \\
\hline 208526_at & -4.4 & OR2F1 & Olfactory receptor, family 2, subfamily F, member 1 \\
\hline 221444_at & -4.1 & TAS2R16 & Taste receptor, type 2 , member 16 \\
\hline 1559244_at & -4.0 & FMN2 & Formin 2 \\
\hline 1553706_at & -4.0 & HTRA4 & HtrA serine peptidase 4 \\
\hline 1553652_a_at & -3.8 & C18orf54 & Chromosome 18 open reading frame 54 \\
\hline 1559270_at & -3.6 & ZFHX4 & Zinc finger homeobox 4 \\
\hline 227401_at & -3.5 & IL17D & Interleukin 17D \\
\hline 206644_at & -3.4 & NROB1 & Nuclear receptor subfamily 0 , group $B$, member 1 \\
\hline 229731_at & -3.3 & FOXS1 & Forkhead box S1 \\
\hline 233897_at & -3.3 & FEZF2 & FEZ family zinc finger 2 \\
\hline 233305_at & -3.3 & NECAB1 & N-terminal EF-hand calcium binding protein 1 \\
\hline 213855_s_at & -3.2 & LIPE & Lipase, hormone-sensitive \\
\hline 207817_at & -3.1 & IFNW1 & Interferon, omega 1 \\
\hline 203059_s_at & -3.1 & PAPSS2 & 3'-phosphoadenosine $5^{\prime}$-phosphosulfate synthase 2 \\
\hline 205893_at & -2.9 & NLGN1 & Neuroligin 1 \\
\hline 222041_at & -2.8 & $\mathrm{DPH} 1$ & DPH1 homolog (Saccharomyces cerevisiae)///candidate tumor suppressor in ovarian cancer 2 \\
\hline 215430_at & -2.8 & GK2 & Glycerol kinase 2 \\
\hline 202855_s_at & 6.6 & SLC16A3 & Solute carrier family 16 , member 3 (monocarboxylic acid transporter 4) \\
\hline 202856_s_at & 4.0 & SLC16A3 & Solute carrier family 16, member 3 (monocarboxylic acid transporter 4) \\
\hline 218505_at & 3.7 & WDR59 & WD repeat domain 59 \\
\hline 34726_at & 3.5 & CACNB3 & Calcium channel, voltage-dependent, beta 3 subunit \\
\hline 211079_s_at & 3.4 & DYRK1A & Dual-specificity tyrosine-(Y)-phosphorylation regulated kinase $1 \mathrm{~A}$ \\
\hline 57163_at & 3.1 & ELOVL1 & Elongation of very long chain fatty acids (FEN1/Elo2, SUR4/Elo3, yeast)-like 1 \\
\hline 225466_at & 3.1 & PATL1 & Protein associated with topoisomerase $\|$ homolog 1 (yeast) \\
\hline 1569701_at & 3.0 & PER3 & CDNA FLJ58931 complete cds, highly similar to Period circadian protein 3 \\
\hline
\end{tabular}

factor (REST). Three C3 TFT gene sets were upregulated in the kiwifruit group. Two of these are grouped by similar promoter motives for known transcription factors: the AhR and hypoxia-inducible factor 1 (HIF1A), respectively. No C3 TFT gene sets were downregulated in the kiwifruit group.

\section{Identification of regulated biological processes among the differentially expressed transcripts}

Up- and downregulated gene transcript lists obtained by Limma, as described in the Methods section, were analysed separately in the downstream applications looking for patterns with regard to biological processes or pathways. A total of 569 and 577 gene transcripts were upregulated by the antioxidant-rich diet intervention and by the kiwifruit intervention, respectively, as compared to the control group (Additional files 8 and 9, Tables S4 and S5). Seventy of these were upregulated in both intervention groups. Compared to the control group, 1162 and 887 gene transcripts were downregulated by the antioxidant-rich diet intervention and by the kiwifruit intervention, respectively (Additional files 10 and 11, Tables S6 and S7). The number of downregulated gene transcripts common for the two interventions was 208.

A paired moderate $t$-test (Limma) was also performed on the $\log _{2}$ values of the control, kiwifruit-rich, and antioxidant-rich diet groups separately. A total of 2415 gene transcripts were differentially modulated by the intervention in the antioxidant-rich diet group (1261

Table 6 Genes that were significantly regulated in the kiwifruit group when compared to controls

\begin{tabular}{|c|c|c|c|}
\hline Probe ID & z-score & Gene Symbol & Gene Title \\
\hline 204810_s_at & -3.3 & CKM & Creatine kinase muscle \\
\hline 217034_at & -4.2 & NTN3 & Immunoglobulin- $\kappa$ light chain variable region (IGKV gene), clone 25 \\
\hline 221299_at & -3.9 & GPR173 & G protein-coupled receptor 173 \\
\hline 1553633_s_at & 4.3 & NHEDC1 & $\mathrm{Na}^{+} / \mathrm{H}^{+}$exchanger domain containing 1 \\
\hline 1557944_s_at & 3.8 & CTNND1 & Catenin (cadherin-associated protein)- $\delta 1$ \\
\hline
\end{tabular}

Positive $z$-score means upregulation in the kiwifruit group whereas negative $z$-score means downregulation. 
Table 7 Regulation of stress relevant gene sets comparing the intervention groups to the controls with regard to changes in gene expression (FDR $\leq 5 \%$ )

\begin{tabular}{|c|c|c|c|c|c|}
\hline \multirow[b]{3}{*}{$\begin{array}{l}\text { GSEA } \\
\text { Gene Set Collections }{ }^{1}\end{array}$} & \multirow[b]{3}{*}{ Number of Gene Sets in Collection ${ }^{2}$} & \multicolumn{4}{|c|}{ Number of Upregulated Gene Sets } \\
\hline & & \multicolumn{2}{|c|}{ Antioxidant-Rich Diet Group } & \multicolumn{2}{|c|}{ Kiwifruit Group } \\
\hline & & Up & Down & Up & Down \\
\hline DNA and repair & 61 & 15 & 0 & 13 & 0 \\
\hline Hypoxia* & 33 & 4 & 0 & 1 & 0 \\
\hline Apoptosis & 206 & 11 & 0 & 4 & 0 \\
\hline Cytokine* & 164 & 1 & 0 & 0 & 0 \\
\hline Interleukin* & 98 & 1 & 0 & 1 & 0 \\
\hline Immune* and response & 62 & 1 & 0 & 1 & 1 \\
\hline Inflammation & 7 & 1 & 0 & 0 & 0 \\
\hline Stress & 91 & 6 & 0 & 0 & 0 \\
\hline Stress and response & 51 & 4 & 0 & 0 & 0 \\
\hline Oxidative and stress & 32 & 2 & 0 & 0 & 0 \\
\hline $\mathrm{C} 3 \mathrm{TFT}^{3}$ & 582 & 13 & 4 & 3 & 0 \\
\hline
\end{tabular}

Collections of gene sets were obtained using a gene set browser from the Broad Institute web site http://www.broad.mit.edu/gsea/ defined by the listed keywords. For some keywords we used truncated search terms as indicated by *

${ }^{2}$ Number of gene sets passing the gene set size filter.

${ }^{3}$ The C3 TFT gene set collection consists of gene sets grouped by common transcription factor binding sites.

downregulated and 1151 upregulated), 2034 were modulated in the kiwifruit group (1064 downregulated and 970 upregulated), whereas the control group had 1622 regulated gene transcripts (700 downregulated and 922 upregulated) $\left(p_{\text {nom }}<5 \%\right)$ (data not shown). These lists confirmed that more gene transcripts were regulated by

Table 8 Regulation of stress relevant gene sets comparing pre and post intervention gene expression within each group (FDR $\leq 5 \%$ )

\begin{tabular}{lcccccc}
\hline \multicolumn{1}{c}{$\begin{array}{c}\text { GSEA } \\
\text { Gene Set Collections }\end{array}$} & \multicolumn{2}{c}{ Number of up regulated Gene Sets } \\
\cline { 2 - 6 } & $\begin{array}{c}\text { Control } \\
\text { Group }\end{array}$ & $\begin{array}{c}\text { Kiwifruit } \\
\text { Group }\end{array}$ & $\begin{array}{c}\text { Antioxidant-Rich } \\
\text { Diet Group }\end{array}$ \\
\cline { 2 - 6 } & Pre & Post & Pre & Post & Pre & Post \\
\hline DNA and repair (61) & 2 & 0 & 0 & 10 & 0 & 20 \\
Hypoxia* (33) & 0 & 0 & 0 & 2 & 0 & 3 \\
Apoptosis (209) & 1 & 3 & 0 & 21 & 0 & 30 \\
Cytokine* (164) & 0 & 3 & 0 & 9 & 0 & 8 \\
Interleukin* (98) & 1 & 1 & 0 & 10 & 0 & 2 \\
Immune* and response (62) & 0 & 2 & 0 & 11 & 0 & 6 \\
Inflammation (7) & 0 & 0 & 0 & 2 & 0 & 0 \\
Stress and response (51) & 0 & 1 & 0 & 0 & 0 & 8 \\
Stress (91) & 0 & 0 & 0 & 0 & 0 & 11 \\
Oxidative and stress (32) & 0 & 0 & 0 & 0 & 0 & 1 \\
C3TFT (582) & 0 & 0 & 1 & 0 & 0 & 45 \\
\hline Collections of & & &
\end{tabular}

${ }^{1}$ Collections of gene sets were obtained using a gene set browser from the Broad Institute website http://www.broad.mit.edu/gsea/ defined by the listed keywords. For some keywords we used truncated search terms as indicated by *

${ }^{2}$ Number of gene sets in each collection passing the gene set size filter is given in parentheses.

${ }^{3}$ The C3 TFT gene set collection consists of gene sets grouped by common transcription factor binding sites. the interventions compared to the control group. The lists obtained from the paired analyses were not used for downstream analysis.

To explore whether a biological process is enriched among the differentially regulated gene transcripts, the GO analysis in J-express was used. This tool tests whether the distribution of a biological process in a list of regulated gene transcripts may be expected when compared to a reference (all GO processes associated with the HG-133 plus 2 chip). A number of biological processes were significantly enriched in the lists of up- and downregulated gene transcripts for both intervention groups (Additional files 12, 13, 14, 15, Tables S8-S11). Biological processes significantly enriched are listed hierarchically. Processes with less than two genes are not included in the table. One gene transcript may map to several biological processes. Biological processes related to 'response to stress', such as DNA repair and defence responses, were significantly enriched in the list of upregulated gene transcripts in both intervention groups and were not found in the downregulated lists. Immune-related processes and processes relevant for regulation of apoptosis were enriched in both up- and downregulated gene transcript lists for both intervention groups.

\section{Discussion}

To our knowledge, this human intervention study is the first in which effects of a plant-based diet have been measured in blood cells using whole genome microarray technology. We have applied a novel application of the GSEA method to test the hypothesis that intake of 
antioxidant-rich foods has an effect on groups of genes associated with cellular stress defence in human blood cells and present data supporting this view.

It is widely accepted that accumulation of molecular and cellular damage, together with progressive failure of maintenance and repair processes, is associated with aging and that plant-based diets protect against agerelated diseases $[2,23]$. Induction of defence pathways by phytochemicals has been proposed to explain the beneficial effects of a plant-based diet [24]. Both energy restriction and regular physical activity are thought to improve life expectancy by inducing adaptive/hormetic responses that protect against molecular damage and subsequent premature aging [25-28]. It is possible that components of plant foods may promote health effects and longevity through similar mechanisms (Figure 3).

One of the few natural compounds that can increase lifespan in animals is resveratrol, a phenolic compound found mainly in the skin of grapes [29]. The antioxidantrich diet used in this intervention study contains not only dietary sources of resveratrol but also thousands of other plant compounds with potential bioefficiency.

Upregulation of nuclear genes related to DNA repair, metabolism, apoptosis and 'stress' response has been reported in several studies in association with longevity [30]. For instance, human centenarians are observed to

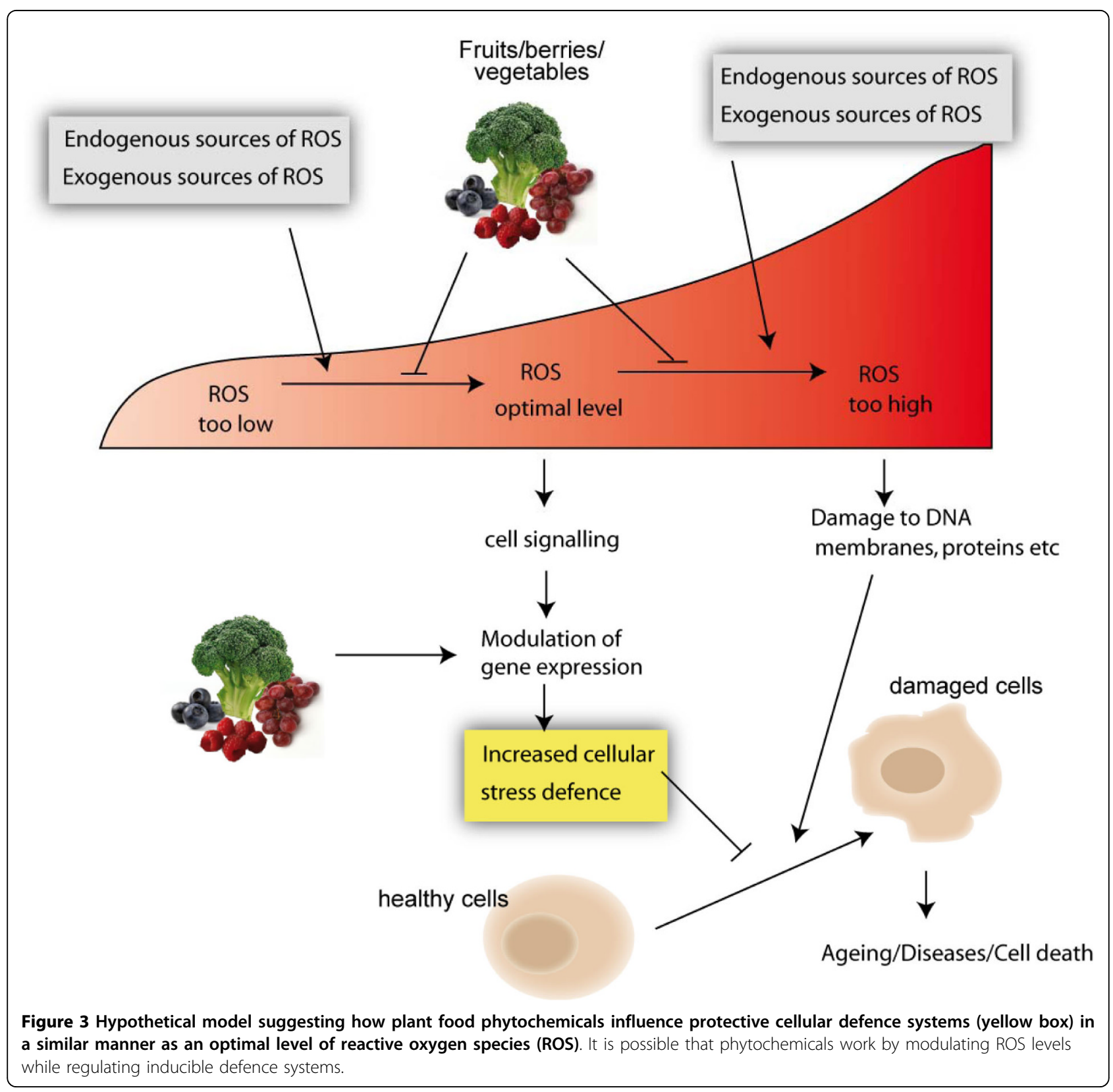


have higher activity levels of poly(ADP-ribose) polymerase-1, which is a key player in the immediate cellular response to stress-induced DNA damage [31]. The transcripts associated with such mechanisms that are upregulated by both the antioxidant-rich diet and the kiwifruit diet may therefore be similarly important for cellular stress defence and maintenance. In agreement with our findings, a moderate and significant upregulation of DNA repair capacity in lymphocytes has been found after a 3-week intervention with cooked carrots [32], and several DNA repair genes were upregulated following a flavonoid-rich diet for 4 weeks [33]. Thus, we suggest that upregulation of genes involved in different DNA repair pathways may explain the observed increase in lymphocyte DNA repair capacity induced by plant-enriched diets. The upregulation of target genes for transcription factors involved in stress responses in our study also offers some potential mechanistic explanations behind the beneficial health effects of plantbased diets. Genes sharing the regulatory xenobiotic response element (XRE) for the aryl hydrocarbon receptor (AHR)/AhR nuclear translocator (ARNT) were upregulated in both intervention groups. Phytochemicals may act as ligands for AHR [34]. Ligand activation of AHR results in dimerisation with ARNT with subsequent binding to XRE. Genes controlled by XRE are involved in Phase I and Phase II reactions whose primary function is to inactivate and eliminate harmful xenobiotic substances. We also found genes with the regulatory motif for hypoxia-inducible factor $1 \mathrm{~A}$ (HIF1A) upregulated in the kiwifruit group. HIF1A controls the hypoxic response occurring at low oxygen tension. Under hypoxia, HIF1A dimerises with ARNT, allowing translocation into the nucleus for induction of gene expression. HIF1A target genes are involved in stress and defence responses [35]. The hypoxic response is also important for proper immune function [36]. Our data therefore support the hypotheses that intake of a diet rich in antioxidants induces expression of detoxification enzymes and proteins involved in defence and stress responses.

Target genes for nuclear respiratory factor 2 (GABP/ NRF2) were upregulated in the antioxidant-rich diet group. Nuclear respiratory factors enhance the expression of nuclear genes involved in mitochondrial function and biogenesis, such as the respiratory subunits, and may be important for human health and longevity $[37,38]$. Thus, GABP/NRF2 may coordinate the cytosolic and mitochondrial protein synthesis. Impairment of mitochondrial function, probably caused by ROS, may be associated with age-related disorders such as type 2 diabetes [39] and Alzheimer's disease [40]. Mitochondrial turnover is higher in young individuals compared to middle-aged and older subjects [41], and genes involved in renewal of mitochondria are downregulated in old mice [42]. Increased mitochondrial number has also been associated with the life-prolonging effects of exercise as well as energy restriction in rats $[43,44]$. The effect of energy restriction on longevity in Caenorhabditis elegans is linked to genes that increase mitochondrial activity throughout the body $[45,46]$. In addition, resveratrol reversed the decline of hepatic mitochondrial number in mice fed a high-energy diet [47]. In this study, we also found genes sharing regulatory motifs for another transcription factor controlling mitochondrial gene transcription, Yin Yang 1 (YY1) [48], to be upregulated in both intervention groups. The antioxidant-rich diets may thus offer a health benefit regarding chronic agerelated diseases by influencing mitochondrial biogenesis via induction of GABP/NRF2 and YY1 target genes.

The antioxidant-rich diet presented here is not only rich in antioxidants, but provided nutrients such as monounsaturated and polyunsaturated lipids and folate (magnesium and iron). The effects on gene expression observed in this intervention study may therefore be attributed not only to phytochemicals but also to other dietary compounds acting via several different mechanisms. However, as similar effects are exerted by the kiwifruit diet, it is plausible to suggest that the observed modulation is mediated mainly by plant-based compounds. Another important aspect is that we have utilised blood cells to assess the effect of the interventions on gene expression. Thus, all the cellular processes found to be regulated by the diets may be of importance for immune function.

\section{Conclusions}

This human dietary intervention is the first to investigate the influences of antioxidant-rich diets on gene expression in whole blood. We observe that gene sets related to DNA repair, hypoxia, apoptosis and immune processes are significantly upregulated by a complex antioxidant-rich diet or by kiwifruits. Our results suggest that the beneficial health effects of a plant-based diet may involve modulation of stress- and defencerelated gene expression important for maintenance of cellular functions. Whether this effect is caused by modulation of redox homeostasis or via other mechanisms needs further investigation. The reported results may contribute to the development of public nutritional advice on antioxidant intake in aspects of prevention of oxidative stress-related diseases and subsequent healthy aging, although the conclusions are preliminary.

\section{Additional material}

Additional file 1: Document S1: A full description of the methods for plasma antioxidant analysis, with references. 
Additional file 2: Figure S1: The figure obtained using Metacore illustrates the leading edge (LE) genes (red bars) (contributing to the significance of the upregulated DNA and repair gene sets in GSEA) in the Nucleotide excision repair (NER) pathway. Red bars indicate LE genes from (1) comparing antioxidant-rich diet group to controls and (2) from comparing kiwifruit diet to controls.

Additional file 3: Figure S2: The figure obtained using Metacore illustrates the leading edge (LE) genes (red bars) (contributing to the significance of the upregulated DNA and repair gene sets in GSEA) represented in the Mismatch repair pathway. Red bars indicate LE genes from (1) comparing antioxidant-rich diet group to controls and (2) from comparing kiwifruit diet to controls.

Additional file 4: Figure S3: The figure obtained using Metacore illustrates the leading edge (LE) genes (red bars) (contributing to the significance of the upregulated DNA and repair gene sets in GSEA) in the response to double -strand breaks-pathway. Red bars indicate LE genes from (1) comparing antioxidant-rich diet group to controls and (2) from comparing kiwifruit diet to controls.

Additional file 5: Table S1: Overview of the gene sets in the stress relevant gene set collections that were upregulated in the antioxidant-rich diet group when compared to controls (GSEA analysis). A brief description of each gene set is included with PubMed ID reference.

Additional file 6: Table S2: Overview of the gene sets in the stress relevant gene set collections that were upregulated in the kiwifruit group when compared to controls (GSEA analysis). A brief description of each gene set is included with PubMed ID reference.

Additional file 7: Table S3: Gene sets in the C3 TFT collection regulated in the antioxidant-rich diet group and kiwifruit group when compared to controls

Additional file 8: Table S4: Gene transcripts upregulated in the antioxidant-rich diet -group vs. controls (LIMMA, $p<5 \%$ )

Additional file 9: Table S5: Gene transcripts upregulated in the kiwifruit-group vs. controls (LIMMA, $p<5 \%$ )

Additional file 10: Table S6: Gene transcripts downregulated in the antioxidant-rich diet-group vs. controls (LIMMA, $p<5 \%$ )

Additional file 11: Table S7: Gene transcripts downregulated in the kiwifruit -group vs. controls (LIMMA, $p<5 \%$ )

Additional file 12: Table S8: Biological processes significantly enriched among the upregulated gene transcripts in the antioxidant-rich diet group.

Additional file 13: Table S9: Biological processes significantly enriched among the downregulated gene transcripts in the antioxidant-rich diet group.

Additional file 14: Table S10: Biological processes significantly enriched among the upregulated gene transcripts in the kiwifruit group.

Additional file 15: Table S11: Biological processes significantly enriched among the downregulated gene transcripts in the kiwifruit group.

\section{Abbreviations}

AA: ascorbic acid; AhR: aryl hydrocarbon receptor; AhR/ARNT(HIF1B): AhR nuclear translocator; ALAT: alanine-aminotransferase; ANOVA: analysis of variance; ARE/EpRE: antioxidant responsive element; BLAST: basic local alignment search tool; BMl: body mass index; CKM: creatine kinase muscle; CTNND1: catenin (cadherin-associated protein)- $\delta \delta 1 ;$ CUTL1L: cutlike $1 ;$ CVD: cardiovascular diseases; DOPAC: 3,4-dihydroxyphenylacetic acid; ELK1: ETS oncogene family; ETS: E-26. FDR: false discovery rate; FRAP: ferric reducing/ antioxidant power assay; GK2: glycerol kinase 2; GO: gene ontology; GPR173: G protein-coupled receptor 173; GSEA: gene set enrichment analysis; HIF1A: hypoxia-inducible factor 1; HUGO: Human Genome Organisation; LIPE: lipase; hormone-sensitive; MIAME: Minimum Information About a Microarray Experiment; NHEDC1: $\mathrm{Na}^{+} / \mathrm{H}^{+}$exchanger domain containing 1; MUFA: monounsaturated fatty acids; NROB1: nuclear receptor subfamily 0 , group B, member 1; NRF2/GABP: nuclear respiratory factor 2/GA binding protein transcription factor; Nrf2/NFE2L2: nuclear factor erythroid 2-related factor 2; NTN3: immunoglobulin kappa light chain variable region; OR2F1: olfactory receptor, family 2 , subfamily $F$, member 1 ; PNA: peptide nucleic acid; PPAR $\gamma$ : peroxisome proliferator-activated receptor- $\gamma$; PUFA: polyunsaturated fatty acids; SFA: saturated fatty acids.

\section{Acknowledgements}

This work was supported by The Throne Holst Foundation, The Research Council of Norway and The Norwegian Cancer Society. We thank all the participants. Thanks also to Siv Fagertun Remberg for preparing and providing a number of food items for the intervention. We also thank Lisa Flakk and Mariann Sommerfeldt for the practical management of the study participants, the bakers at 'Åpent Bakeri' in Oslo for making the bread and 'Kraft Foods' in Norway for the chocolate.

\section{Author details}

${ }^{1}$ Department of Nutrition, Institute of Basic Medical Sciences, Faculty of Medicine, University of Oslo, Norway. ${ }^{2}$ Department of Biostatistics, Institute of Basic Medical Sciences, Faculty of Medicine, University of Oslo, Norway. ${ }^{3}$ Norwegian Computing Centre, Oslo, Norway. ${ }^{4}$ Centre for Occupational and Environmental Medicine, Rikshospitalet-Radiumhospitalet Medical Center, Oslo, Norway. ${ }^{5}$ Department of Chronic Disease Prevention, National Institute for Health and Welfare, Helsinki, Finland. ${ }^{6}$ Department of Preventive Cardiology, Oslo University Hospital, Ullevål, Oslo, Norway. ${ }^{7}$ Centre for Clinical Heart Research, Department of Cardiology, Oslo University Hospital, Ullevål, Oslo, Norway. ${ }^{8}$ Department of Biochemistry, Institute of Basic Medical Sciences, Faculty of Medicine, University of Oslo, Norway.

\section{Authors' contributions}

RB and SKB formulated the present hypothesis. SKB, MCM, MT, MH, AK, MS, IS, JØM, AKD, PL, CAD, HA, ST, AC, RB contributed to the clinical study design, intervention, and sample collection. MCM was responsible for RNA isolation. SKB was responsible for quality control of samples and responsible for the statistical analysis, together with MT and MH. SHT did the hybridization to the arrays. AK was responsible for analysis of plasma carotenoids. IE was responsible for the analysis of polyphenols in plasma. SKB and MCM were responsible for interpreting the results and drafting the manuscript. All authors approved the final version before submission.

\section{Competing interests}

The following authors declare no competing interest; SKB, MCM, MT, MH, SHT, AK, IE MS, IS, JØM, AKD, PL, HA, ST and AC. RB and CAD have an interest in Bioindex AS and Vitas AS, and RB has an interest in Cgene AS. Bioindex and Cgene were established by Birkeland Innovation, the technology transfer office at the University of Oslo, while Vitas was established by Oslo Innovation Center.

Received: 5 August 2010 Accepted: 16 September 2010 Published: 16 September 2010

\section{References}

1. Hu FB: Plant-based foods and prevention of cardiovascular disease: an overview. Am J Clin Nutr 2003, 78:544S-551S.

2. World Cancer Research Fund/American Institute for Cancer Research: Food Nutrition, Physical Activity, and the Prevention of Cancer: a Global Perspective. Washington DC 2007.

3. Bjelakovic G, Nikolova D, Gluud LL, Simonetti RG, Gluud C: Mortality in randomized trials of antioxidant supplements for primary and secondary prevention: systematic review and meta-analysis. JAMA 2007, 297:842-857.

4. Lippman SM, Klein EA, Goodman PJ, Lucia MS, Thompson IM, Ford LG, Parnes HL, Minasian LM, Gaziano JM, Hartline JA, et al: Effect of selenium and vitamin $E$ on risk of prostate cancer and other cancers: the Selenium and Vitamin E Cancer Prevention Trial (SELECT). JAMA 2009, 301:39-51. 
5. Kensler TW, Wakabayashi N, Biswal S: Cell survival responses to environmental stresses via the Keap1-Nrf2-ARE pathway. Annu Rev Pharmacol Toxicol 2007, 47:89-116.

6. Landis GN, Tower J: Superoxide dismutase evolution and life span regulation. Mech Ageing Dev 2005, 126:365-379.

7. Jeong WS, Jun M, Kong AN: Nrf2: a potential molecular target for cance chemoprevention by natural compounds. Antioxid Redox Signal 2006 , 8:99-106.

8. Ben-Dor A, Steiner M, Gheber L, Danilenko M, Dubi N, Linnewiel K, Zick A Sharoni $Y$, Levy J: Carotenoids activate the antioxidant response element transcription system. Mol Cancer Ther 2005, 4:177-186.

9. Wagner AE, Ernst I, lori R, Desel C, Rimbach G: Sulforaphane but not ascorbigen, indole-3-carbinole and ascorbic acid activates the transcription factor Nrf2 and induces phase- 2 and antioxidant enzymes in human keratinocytes in culture. Exp Dermatol 2009, 19:137-44.

10. Hayes JD, McLellan LI: Glutathione and glutathione-dependent enzymes represent a co-ordinately regulated defence against oxidative stress. Free Radic Res 1999, 31:273-300.

11. Hoeijmakers JH: DNA damage, aging, and cancer. N Engl J Med 2009, 361:1475-1485

12. Harper JW, Elledge SJ: The DNA damage response: ten years after. Mol Cell 2007, 28:739-745.

13. Janssen-Heininger $\mathrm{YM}$, Mossman BT, Heintz NH, Forman $\mathrm{HJ}$, Kalyanaraman B, Finkel T, Stamler JS, Rhee SG, van d V: Redox-based regulation of signal transduction: principles, pitfalls, and promises. Free Radic Biol Med 2008, 45:1-17.

14. Ristow M, Zarse K, Oberbach A, Kloting N, Birringer M, Kiehntopf M, Stumvoll M, Kahn CR, Bluher M: Antioxidants prevent health-promoting effects of physical exercise in humans. Proc Natl Acad Sci USA 2009, 106:8665-8670

15. Carlsen MH, Halvorsen BL, Holte K, Bohn SK, Dragland S, Sampson L, Willey $\mathrm{C}$, Senoo $\mathrm{H}$, Umezono $Y$, Sanada $\mathrm{C}$, et al: The total antioxidant content of more than 3100 foods, beverages, spices, herbs and supplements used worldwide. Nutr J 2010, 9:3.

16. National Nutrient Database for Standard Reference, USDA. Release 22 2009 [http://www.ars.usda.gov/ba/bhnrc/ndl], Accessed 12 February 2010.

17. Erlund I, Alfthan G, Siren H, Ariniemi K, Aro A: Validated method for the quantitation of quercetin from human plasma using high-performance liquid chromatography with electrochemical detection. J Chromatogr $B$ Biomed Sci Appl 1999, 727:179-189.

18. Kilkkinen A, Erlund I, Virtanen MJ, Alfthan G, Ariniemi K, Virtamo J: Serum enterolactone concentration and the risk of coronary heart disease in a case-cohort study of Finnish male smokers. Am J Epidemiol 2006, 163:687-693

19. Ishwaran H, Rao JS, Kogalur UB: BAMarraytrade mark: Java software for Bayesian analysis of variance for microarray data. BMC Bioinformatics 2006, 7:59.

20. Smyth GK: Linear models and empirical bayes methods for assessing differential expression in microarray experiments. Stat App/ Genet Mol Biol 2004, 3:Article3.

21. Mootha VK, Lindgren CM, Eriksson KF, Subramanian A, Sihag S, Lehar J, Puigserver P, Carlsson E, Ridderstrale M, Laurila E, et al: PGC-1alpharesponsive genes involved in oxidative phosphorylation are coordinately downregulated in human diabetes. Nat Genet 2003, 34:267-273.

22. Subramanian A, Tamayo P, Mootha VK, Mukherjee S, Ebert BL, Gillette MA, Paulovich A, Pomeroy SL, Golub TR, Lander ES, et al: Gene set enrichment analysis: a knowledge-based approach for interpreting genome-wide expression profiles. Proc Natl Acad Sci USA 2005, 102:15545-15550.

23. Van HL, MCCoin M, Kris-Etherton PM, Burke F, Carson JA, Champagne CM, Karmally W, Sikand G: The evidence for dietary prevention and treatment of cardiovascular disease. J Am Diet Assoc 2008, 108:287-331.

24. Mattson MP: Dietary factors, hormesis and health. Ageing Res Rev 2008 7:43-48

25. Radak Z, Chung HY, Goto S: Exercise and hormesis: oxidative stressrelated adaptation for successful aging. Biogerontology 2005, 6:71-75

26. Suwa M, Nakano H, Radak Z, Kumagai S: Endurance exercise increases the SIRT1 and peroxisome proliferator-activated receptor gamma coactivator-1alpha protein expressions in rat skeletal muscle. Metabolism 2008, 57:986-998.

27. Lin SJ, Defossez PA, Guarente L: Requirement of NAD and SIR2 for lifespan extension by calorie restriction in Saccharomyces cerevisiae. Science 2000, 289:2126-2128

28. Lamming DW, Latorre-Esteves M, Medvedik O, Wong SN, Tsang FA, Wang C, Lin SJ, Sinclair DA: HST2 mediates SIR2-independent life-span extension by calorie restriction. Science 2005, 309:1861-1864.

29. Wood JG, Rogina B, Lavu S, Howitz K, Helfand SL, Tatar M, Sinclair D: Sirtuin activators mimic caloric restriction and delay ageing in metazoans. Nature 2004, 430:686-689.

30. Butow RA, Avadhani NG: Mitochondrial signaling: the retrograde response. Mol Cell 2004, 14:1-15.

31. Muiras ML, Muller M, Schachter F, Burkle A: Increased poly(ADP-ribose) polymerase activity in lymphoblastoid cell lines from centenarians. J Mol Med 1998, 76:346-354.

32. Astley SB, Elliott RM, Archer DB, Southon S: Evidence that dietary supplementation with carotenoids and carotenoid-rich foods modulates the DNA damage: repair balance in human lymphocytes. Br J Nutr 2004, 91:63-72.

33. Guarrera S, Sacerdote C, Fiorini L, Marsala R, Polidoro S, Gamberini S, Saletta F, Malaveille C, Talaska G, Vineis P, et al: Expression of DNA repair and metabolic genes in response to a flavonoid-rich diet. Br J Nutr 2007, 98:525-533.

34. Ciolino HP, Daschner PJ, Yeh GC: Dietary flavonols quercetin and kaempferol are ligands of the aryl hydrocarbon receptor that affect CYP1A1 transcription differentially. Biochem J 1999, 340(Pt 3):715-722.

35. Semenza GL: Targeting HIF-1 for cancer therapy. Nat Rev Cancer 2003, 3:721-732

36. Cramer T, Yamanishi $Y$, Clausen BE, Forster I, Pawlinski R, Mackman N, Haase $\mathrm{VH}$, Jaenisch $\mathrm{R}$, Corr $\mathrm{M}$, Nizet $\mathrm{V}$, et al: HIF-1alpha is essential for myeloid cell-mediated inflammation. Cell 2003, 112:645-657.

37. Patti ME, Butte AJ, Crunkhorn S, Cusi K, Berria R, Kashyap S, Miyazaki Y, Kohane I, Costello M, Saccone R, et al: Coordinated reduction of genes of oxidative metabolism in humans with insulin resistance and diabetes: potential role of PGC1 and NRF1. Proc Natl Acad Sci USA 2003, 100:8466-8471.

38. Pandit A, Vadnal J, Houston S, Freeman E, McDonough J: Impaired regulation of electron transport chain subunit genes by nuclear respiratory factor 2 in multiple sclerosis. J Neurol Sci 2009, 279:14-20.

39. Huang $\mathrm{JH}$, Hood DA: Age-associated mitochondrial dysfunction in skeletal muscle: Contributing factors and suggestions for long-term interventions. IUBMB Life 2009, 61:201-214.

40. Gibson GE, Karuppagounder SS, Shi Q: Oxidant-induced changes in mitochondria and calcium dynamics in the pathophysiology of Alzheimer's disease. Ann N Y Acad Sci 2008, 1147:221-232.

41. Rooyackers OE, Adey DB, Ades PA, Nair KS: Effect of age on in vivo rates of mitochondrial protein synthesis in human skeletal muscle. Proc Natl Acad Sci USA 1996, 93:15364-15369.

42. Lee CK, Klopp RG, Weindruch R, Prolla TA: Gene expression profile of aging and its retardation by caloric restriction. Science 1999 285:1390-1393.

43. Nisoli E, Tonello C, Cardile A, Cozzi V, Bracale R, Tedesco L, Falcone S, Valerio A, Cantoni O, Clementi $\mathrm{E}$, et al: Calorie restriction promotes mitochondrial biogenesis by inducing the expression of eNOS. Science 2005, 310:314-317.

44. Lopez-Lluch G, Hunt N, Jones B, Zhu M, Jamieson H, Hilmer S, Cascajo MV Allard J, Ingram DK, Navas $P$, et al: Calorie restriction induces mitochondrial biogenesis and bioenergetic efficiency. Proc Natl Acad SCi USA 2006, 103:1768-1773.

45. Panowski SH, Wolff S, Aguilaniu H, Durieux J, Dillin A: PHA-4/Foxa mediates diet-restriction-induced longevity of C. elegans. Nature 2007 447:550-555.

46. Bishop NA, Guarente L: Two neurons mediate diet-restriction-induced longevity in C. elegans. Nature 2007, 447:545-549. 
47. Baur JA, Pearson K, Price NL, Jamieson HA, Lerin C, Kalra A, Prabhu W, Allard JS, Lopez-Lluch G, Lewis K, et al: Resveratrol improves health and survival of mice on a high-calorie diet. Nature 2006, 444:337-342.

48. Cunningham JT, Rodgers JT, Arlow DH, Vazquez F, Mootha VK, Puigserver P. mTOR controls mitochondrial oxidative function through a YY1-PGC1alpha transcriptional complex. Nature 2007, 450:736-740.

\section{Pre-publication history}

The pre-publication history for this paper can be accessed here: http://www.biomedcentral.com/1741-7015/8/54/prepub

doi:10.1186/1741-7015-8-54

Cite this article as: Bøhn et al:: Blood cell gene expression associated with cellular stress defense is modulated by antioxidant-rich food in a randomised controlled clinical trial of male smokers. BMC Medicine 2010 8:54.

\section{Submit your next manuscript to BioMed Central} and take full advantage of:

- Convenient online submission

- Thorough peer review

- No space constraints or color figure charges

- Immediate publication on acceptance

- Inclusion in PubMed, CAS, Scopus and Google Scholar

- Research which is freely available for redistribution

Submit your manuscript at www.biomedcentral.com/submit 